\title{
Absenteeism of Frontline Healthcare Workers During Covid-19: the Need for a Framework of Support
}

\author{
$\operatorname{Omar}_{\operatorname{Tujjar}^{1}}{ }^{\mathbb{D}} \cdot$ Martina Simonelli $^{1}$
}

Accepted: 20 October 2020 / Published online: 28 October 2020

(C) Springer Nature Switzerland AG 2020

For the most part, healthcare workers (HCWs) espouse a strong work ethic where people have been making heroic stances in the fight against Covid-19; HCWs across the board have been turning up for work, ready and willing to volunteer for additional hours and duties, often outside of their normal remit and scope of practice. A smaller cohort of these workers, however, has been subject to absenteeism.

Within the broad definition of 'absenteeism', there are a number of sub-divisions that range from those with clear and fully justifiable reasons for removing themselves from the front line (such as those who got in close contact with a confirmed case) to those who are engaging in what we might call straightforward defection - which is conceivably a very rare eventuality.

There are no figures or solid factual evidence in report form that support this phenomenon. The problem does exist, however, and it has manifested itself in anecdotal evidence from our own local experience and from that of several colleagues working in hospitals in other countries. It is therefore important, in the first instance, to conduct research in this area in order to establish some numerical values on the extent and cost of the problem.

Having established that the problem exists and begun a process that will go some way towards quantifying it, research needs to be done on the various possible causes of

This article is part of the Topical Collection on Covid-19

Dr. Omar Tujjar, Consultant in Anaesthesiology, Intensive Care and Pain Medicine MD, MA

Dr. Martina Simonelli, Consultant in Anaesthesiology, Intensive Care and Pain Medicine MD

Omar Tujjar

Omar.Tujjar@hse.ie

Martina Simonelli

Martina.Simonelli@hse.ie

1 Department of Anaesthesia, Intensive Care and Pain Medicine, Sligo University Hospital, The Mall, Sligo, Ireland absenteeism, remembering once again that this is a phenomenon with various shades of severity. All of the possible causes and effects need to be teased out and from this analysis, a solid framework of support needs to be discussed that will serve healthcare services not only in this current crisis but also in the inevitable crises that are to come.

The first set of causes is centred on the responsibilities of family life. Childcare is a significant part of this. The universal closure of schools and childcare facilities during the lockdown left many HCWs without any means of taking care of their children. Those who would normally rely on grandparents to take up this role were often prevented by the necessity of cocooning the elderly. Similarly, there is the issue of elderly care, when someone is obliged to spend time at home looking after an elderly relative whose needs must come before work duties. The conditions of lockdown in most countries have put into even sharper focus the needs of elderly at home and have placed an added burden on those who have to look after them and carry out their daily chores. In the same way, those who have any relatives with special needs in the home have found their availability for work more compromised than ever before during a time of pandemic when their professional services are most in demand.

Pregnancy is a cause for absenteeism that has emerged more acutely during this pandemic. The fear that exposure to an unfamiliar infection could have an adverse effect on the health of the mother-to-be and on the unborn child has driven some HCWs to request early maternity or sick leave.

Those with any comorbidity will suffer similar concerns in terms of the effects of an undefined infection on their health. The fear of the unknown makes anyone in such a vulnerable situation more likely to avoid coming to work out of natural self-preservation instincts.

Then there is the issue of stress and burnout. Virtually all workers on the front line are working long, exhausting hours and the resultant rise in levels of stress induced by fatigue are considerable. Once again, the fear of the unknown plays its part-particularly in the form of the 
anticipation of a surge with its debilitating impact on mental health. All the while, the ongoing stress of the situation leads to conflict between colleagues as multiple stress issues and individual personal issues and fears come into sharp relief and are brought to the surface.

Strains are also put on the ability of staff members to have confidence in the systems in place to ensure that their own safety and that of patients are not being diminished or compromised in any way. In these times, fears arise as to just how safe the working environment is and just what the measures in place are to minimise to an absolute extent the risks of passing on infections and taking them home. Is there enough PPE material in place, for example? Or if not, is it on its way? Is it of good quality?

The other source of pressure on the system that can lead to demoralisation and absenteeism is that of staff redeployment. With so many people being asked to do so much extra-both in terms of hours and of additional duties and redeployment to areas for which they have no specific training - it's only a matter of time before the system catches up with itself and pressures from individuals and union representatives begin to reassert themselves on the circumstances. The situation of all hands to the pump can only last for a short time before legal, union, and personal issues need to be reassessed. The strong temptation amongst management is to assume that the situation will continue unhindered as long as the crisis continues but suddenly, there is rising absenteeism because the worst of the crisis has passed and some of those who were putting aside legal, insurance and other considerations will now gravitate back to their default positions.

The cumulative effect of all these causes of absenteeism is for more pressure to be put on the system in all areas. Beginning with the strain on the roster itself, the increasing shortage of HCWs means that staff will have to be redeployed from other areas. This, as outlined above, creates certain problems of itself, not to mention increasing risk with regard to insurance considerations and deterioration of relationships with workers' unions and of overall staff morale. Moreover, the level of care may be affected. This is particularly true in the intensive care unit, where deployment of non-specialised ICU staff to compensate the workforce shortage is inherently associated with an increased risk of adverse events [1].

In the absence of research to define the nature and extent of all these issues, it is difficult to be prescriptive about their solutions. However, a number of speculations could provide the basis for a conversation aimed at defining a framework of support for future crises.

Creative yet convincing solutions for the childminding issue must be sought. While we have all been deeply gratified by the huge outpouring of goodwill, and indeed offers of support and help with childcare during the crisis, this voluntary effort cannot be expected to take the place of trained and certified carers that are managed by a recognised authority.
Various locations for setting up a childcare centre in an unused school or kindergarten, for example, could be researched, where the necessary protocols of social distancing and hand hygiene would apply. Weekly testing should be offered for all childminding and care staff. The issue of insurance cover must be addressed, and special insurance cover may need to be implemented. Childminding and care staff in these situations should be highly remunerated and should be supplied with adequate breaks and periods of time off.

Regarding vulnerable HCWs (for instance pregnant or immunocompromised), the effects of absenteeism could be lessened by ensuring that such staff are redeployed to no-risk areas. Moreover, could specialists who fall into this category continue to offer their skills and expertise from home using the available technology? If an experienced but home-based ICU nurse can virtually accompany a non-ICU nurse, those valuable skills can continue to be brought to bear on the pandemic.

The area of rewards is very important too. Aside from the obvious one of increasing remuneration, other options need to be explored and teased out. If budgets do not allow for a salary increase, perhaps a short-term bonus system could be implemented, or more significant tax breaks could be negotiated for those working on the front line? There may be other areas to look at too of a non-financial nature, public acts of appreciation in the mainstream and social media, for example.

Leadership needs to be at its sharpest during a pandemic. To inspire confidence, it must display strong characteristics of solidity and knowledgeability. Staff needs to feel safe and protected. Managers must take a strong lead on headline issues such as the supply of PPE (both on its quality and quantity), clear infection control and contamination pathways, and follow-up contact tracing [2].

Clarification of the chain of command from the top of the healthcare system down would help to ensure that procurement processes are structured and clear. HCWs on the ground need to know who to call when resources are urgently required. While these structures improved as the crisis progressed, their fuzziness at the beginning of the emergency lead to significant levels of frustration and anxiety. On a practical level, that essentially boils down to being able to ask for things in a simple, safe, and clear way.

The same clarity needs to be applied to the whole area of liabilities and responsibilities in the times of necessary expanding scope of practice [3]. Redeploying staff to different areas of the hospital without specialised training - and even taking on students in order to deal with a surge - would leave the hospital open to these ancillary risks which should be closed off in advance of any new pandemic.

In terms of workers' mental well-being, more proactive wellness and support programmes for HCWs should also be investigated [4]. Setting up these programmes on an opt-out rather than an opt-in basis would help to remedy the signs of burnout before it develops. 
Fig. 1 Conceptual framework for the support of frontline healthcare workers during a pandemic

\section{Government}

\section{Healthcare System}

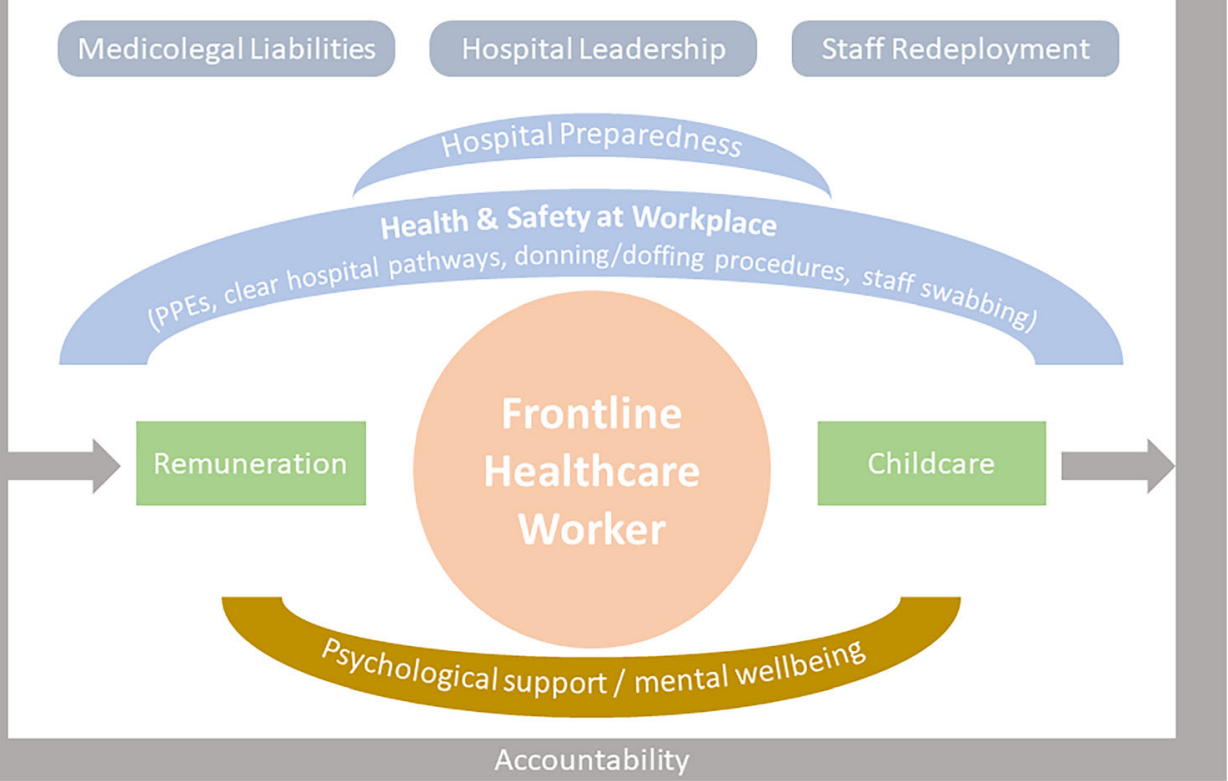

Lastly, should absenteeism occur with no apparently justifiable reason and despite all the support made available, a framework of accountability should be explored by healthcare systems [5]: The front lines cannot be abandoned without a specific reason.

To summarise, we propose a conceptual model where the frontline HCW is at the centre (Fig. 1). This model contemplates support from the healthcare system under the form of a clear structure of operations, a clear stance of medicolegal liabilities, the recruitment and redeployment of workforce, and the assurance of hospital preparedness. The latter is crucial to guarantee health and safety at the workplace and reassure HCWs about the safety of their working environment. In particular, availability of adequate PPEs, clarity on hospital pathways and donning/doffing procedures, and accessibility to swabbing tests for staff must all be in place. Government and society must support the frontline HCWs during times of crisis by offloading the responsibilities of child and family care and promote their mental well-being.

For most healthcare systems around the world, these are unchartered and often terrifying times. In navigating the unknown waters of the Covid-19 pandemic, errors of both a fundamental and minor nature have been committed by many, while unexpected issues challenged healthcare authorities and providers on a daily basis. Although yet unquantified, the challenge of hospital absenteeism is a serious threat, and a serious conversation on its causes, effects, and possible solutions must take place. A framework of support must be defined to prevent absenteeism and be in a state of preparedness for the possibility of a future pandemic.

\section{Compliance with Ethical Standards}

Conflict of Interest The authors declare that they have no conflict of interest.

\section{References}

1. Einav S, Hick JL, Hanfling D, Erstad BL, Toner ES, Branson RD, et al. Surge capacity logistics: care of the critically ill and injured during pandemics and disasters: CHEST consensus statement. Chest. 2014;146(4):e17S-43S.

2. Taylor BL, Montgomery HE, Rhodes A, Sprung CL. European Society of Intensive Care Medicine's Task Force for intensive care unit triage during an influenza epidemic or mass disaster. Chapter 6. Protection of patients and staff during a pandemic. Recommendations and standard operating procedures for intensive care unit and hospital preparations for an influenza epidemic or mass disaster. Intensive Care Med. 2010;36(Suppl 1):S45-54.

3. Courtney B, Hodge JG Jr, Toner ES, Roxland BE, Penn MS, Devereaux AV, et al. Legal preparedness: care of the critically ill and injured during pandemics and disasters: CHEST consensus statement. Chest. 2014;146(4):e134S-44S.

4. Dewey C, Hingle S, Goelz E, Linzer M. Supporting clinicians during the COVID-19 pandemic. Ann Intern Med. 2020;172(11):752-3.

5. Wiener CL. The elusive quest: accountability in hospitals. New Brunswick: Transaction Publishers; 2000.

Publisher's Note Springer Nature remains neutral with regard to jurisdictional claims in published maps and institutional affiliations. 